\title{
The scientific marketplace
}

\author{
To ensure that their work gets the funding and the attention it deserves, scientists need to engage with \\ different stakeholders. Concepts from marketing could help them increase the impact of their efforts.
}

Sometimes doing good science is not enough. Today, researchers have to make their publications stand out from the stack of nearly 800,000 science and engineering manuscripts that are published each year ${ }^{1}$, recent $\mathrm{PhD}$ graduates and postdocs face historically low employment prospects in academia ${ }^{2}$, and principal investigators compete over shrinking government funding ${ }^{3}$. What is more, some scientists also have to convince the media and the general public of the validity of their work, such as the reality of climate change or the fact that the Large Hadron Collider will not be producing any black holes. Clearly, making oneself seen and heard as a scientist has never been more demanding, and the growing size of the scientific community and the limitations of the resources it relies on are likely to make this process more difficult.

One answer to these challenges lies in a more professional approach to communicating research activities and results: science marketing. Marketing a concept from the business world that probably provokes ambiguous feelings in scientists - has recently gained interest among science managers. Only last year, the Dutch initiative Science Alliance organized the first international conference on science marketing ${ }^{4}$, acknowledging that scientists need to deliver and communicate their results to a variety of different stakeholders, such as their colleagues, funding agencies, politicians, the media and the public.

This Focus issue explores the promises and pitfalls of science marketing. Of course, marketing does not mean relentless selfpromotion and advertising. Rather, in the view of many professional marketers the 'marketing mix' - the different factors that determine the success of a brand or a product today - has shifted towards a consumer-focused setting, in which customer requirements and communication are key ${ }^{5}$. We discuss the applicability of such concepts to the scientific 'business' in an Interview with Marc Kuchner, an astrophysicist who has recently written a book on science marketing ${ }^{6}$.

The notion that scientists, knowingly or unaware, market their work is far from new. As early as 1983, marketing experts Paul Peter and Jerry Olson postulated that science is the marketing of theories ${ }^{7}$. In their

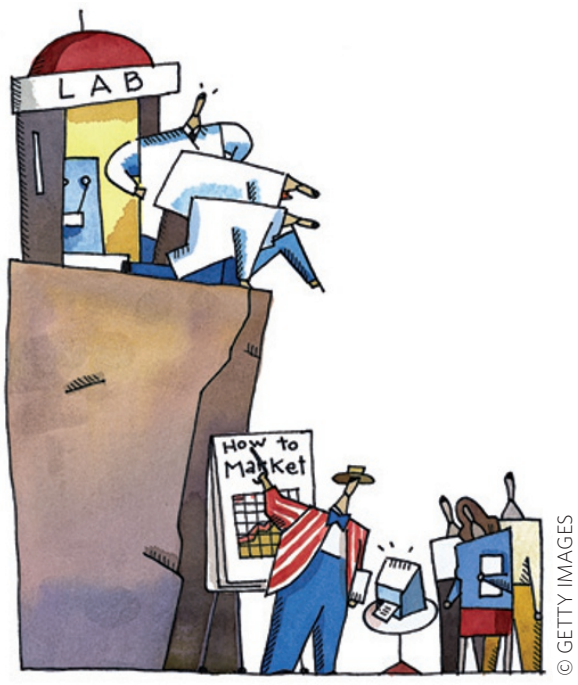

such different audiences means that scientists need to adapt their communication strategy. Whereas peers demand scientific rigor, talking to the public requires simplifying ideas, avoiding technical jargon and presenting a broad view. This is not equally easy in all areas, and it does not come naturally to everyone.

According to Kuchner, the core of all science marketing should be branding and relationship building. Branding ranges from the choice of research topic to the image that scientists choose to convey towards colleagues and the media. Relationship building, on the other hand, involves mutually beneficial interactions such as sharing ideas or data.

In a Commentary that discusses the latest internet-based communication services, blogger and cancer researcher Martin Fenner makes clear that there have never been more tools available that allow scientists to do exactly that ${ }^{9}$. One of the most basic online tools for branding is that of researcher profiles, which can serve as a first point of contact and a convenient hub that connects scientific works. Online data sharing may help colleagues or enable new collaborations. And for those with a more outgoing approach, communication is facilitated through social networks and blogs. Arguably, citizen science projects contribute more to public enthusiasm for science than scores of press releases.

However, as in business, the online marketplace also has pitfalls, and initiatives such as post-publication peer review may expose critical 'customer comments'. Hence, the starting point of all marketing efforts should always be good science. Creativity and quality are more important than quantity in building a scientific reputation ${ }^{10}$, and a focus on these values serves scientists as much as their customers.

\footnotetext{
References

1. National Science Foundation Science and Engineering Indicators 2012; http://www.nsf.gov/statistics/seind 12

2. Nature 472, 276-279 (2011).

3. Nature Mater. 10, 407 (2011)

4. http://www.sciencemarketing2011.com

. http://www.cluetrain.com

6. Nature Mater. 11, 264-265 (2012).

. Peter, J. P. \& Olson, J. C. J. Marketing 47, 111-125 (1983).

8. Kuhn, T. S. The Structure of Scientific Revolutions (Univ. Chicago Press, 1962).

9. Nature Mater. 11, 261-263 (2012).

10. Dewett, T. \& Denisi, A. S. Scientometrics 60, 249-272 (2004).
} 